\title{
MEDIDAS DE PRODUTIVIDADE: DILEMAS DA AGRICULTURA FAMILIAR
}

Eliseu Alves ${ }^{1}$

Resumo - O objetivo deste trabalho é isolar, em pequeno número, as premissas que têm permeado as discussões sobre agricultura familiar. Depois, por métodos elementares, elas são dedutivamente exploradas. Mostra-se que a produtividade da terra é, incorretamente, interpretada e que se deixa de lado a produtividade do trabalho, que, no contexto desse tipo de agricultura, é uma medida de bem-estar. Argumenta-se que, quando a agricultura familiar adota os métodos de decisão da agricultura capitalista, as duas medidas de produtividade devem ser substituídas pela produtividade total. A agricultura familiar escolhe uma cesta de produtos com base em seu próprio interesse e não no bem-estar dos citadinos, razão por que é pouco relevante o argumento de que produz os alimentos da cesta de consumo dos citadinos mais pobres. Deve-se interpretar esse tipo de evidência negativamente, visto que significa a existência de restrições ao bem-estar da família. Finalmente, considera-se um conjunto de dilemas, a maioria deles relacionados com as dificuldades de manter as premissas, num contexto de uma agricultura capitalista dinâmica.

Palavras-chave: Agricultura familiar, agricultura comercial, medidas de produtividade.

\footnotetext{
${ }^{1}$ Eliseu Alves é pesquisador da Embrapa.

Recebido em 12/08/2003 Aceito em 11/09/2003
} 


\section{Introdução}

A melhor linha de defesa da agricultura familiar fundamenta-se nos milhões de agricultores dessa categoria, que é grande empregadora e remunera mal o trabalho familiar, razão pela qual precisa ser ajudada. A produtividade da terra, muito empregada atualmente, não indica que a agricultura familiar seja mais eficiente, apenas mostra a expressividade desta, outra maneira de demonstrar sua importância. Precisa-se ter em mente que conceitos corretos fortalecem a defesa da agricultura familiar. É irrelevante o argumento de que ela abasteça o mercado urbano de alimentos. Os conceitos incorretos alimentam de argumentos os que não vêem com bons olhos as políticas públicas para a agricultura familiar.

A posição do autor é de defesa da agricultura familiar e de políticas públicas que a estimulem, mas expõe a vulnerabilidade de muitos argumentos em seu favor, o que pode ser interpretado erroneamente.

O trabalho está dividido em cinco seções: definição das medidas de produtividade, modelo cultural, modelo de produção, dilemas da proposta da agricultura familiar e conclusões. O objetivo deste trabalho é captar a essência das discussões em premissas e discutir suas implicações.

\section{Definição das medidas de produtividade}

No contexto da agricultura familiar, duas medidas de produtividade permeiam a discussão: produtividade da terra e produtividade do trabaho. Uma terceira medida é a produtividade total.

Como a agricultura familiar produz vários produtos, a agregação, para se obter a renda bruta, é a soma dos valores dos produtos produzidos. É uma agregação pobre, porque entram os preços de mercado, muito influenciados pela agricultura comercial, embora seja uma agregação cômoda e factível.

A produtividade do trabalho é definida pela renda bruta dividida pelo número de trabalhadores. Problemas de agregação também estão pre- 
sentes, e o mais correto era ter equivalente-homem no lugar de trabalhadores. No caso de dados censitários, trata-se de uma missão impossível.

A produtividade da terra é equivalente à renda bruta dividida pela área total. Considerar o denominador como a área cultivada mais pastagens e outros itens que indicam terra explorada não se ajusta ao conceito da agricultura familiar. $\mathrm{O}$ que interessa é o potencial de produção da terra, e a área total é uma proxy com vários problemas, entre eles, comparar terras pobres com férteis.

Um problema relativo à produtividade do trabalho é a contaminação que tem com a produtividade da terra, como se expressa na identidade abaixo:

$\frac{R B}{L} \equiv \frac{R B}{A} * \frac{A}{L}$, em que $\mathrm{RB}$ representa a renda bruta; $\mathrm{L}$, trabalho; e A, área do estabelecimento. $\mathrm{O}$ termo da esquerda é a produtividade do trabalho, como foi definida. O primeiro termo da direita é a produtividade da terra, novamente, como definida: muito influenciada por tecnologias que poupam terra, como fertilizantes. O segundo termo da direita é outra medida da produtividade do trabalho, que expressa a área que cada trabalhador é capaz de cultivar e é dependente dos índices de mecanização. Na realidade, mede a capacidade de o trabalhador explorar toda a área de que dispõe. Quando é muito baixa, comparada com padrões da agricultura familiar moderna, significa grande possibilidade de a família ter que deixar área ociosa. O produto dos dois termos da direita resulta na produtividade do trabalho, e, aí, nasce a contaminação.

A primeira lição é que não faz sentido estimar simultaneamente, como definidas, a produtividade da terra e a do trabalho, ou uma ou outra, rigorosamente falando. No entanto, é legítimo estimar a produtividade da terra e a área que cada trabalhador é capaz de cultivar.

Quando a agricultura familiar caminha para a agricultura comercial, o 
agricultor passa a comprar insumos no mercado e a vender produtos. Então, a medida mais apropriada é a produtividade total, ou seja, a renda bruta dividida pelo gastos com todos os insumos, que expressa a produtividade de todos os insumos. Se há dados mais detalhados, o que raramente acontece em nível nacional, estadual e municipal, medidas de eficiência podem ser derivadas da fronteira estocástica e por meio de métodos não-paramétricos. A discussão destes foge ao escopo deste trabalho.

Apresentaremos, a seguir, o modelo cultural, que visa expressar as premissas que lastreiam as discussões em curso e as deduções que delas decorrem.

\section{Modelo cultural}

As seguintes premissas caracterizam o modelo:

a) Quando há apenas dois insumos, trabalho e terra, e como ambos são da família, a produção máxima corresponde ao bem-estar máximo que a família pode obter do estabelecimento. Uma expressão deste bem-estar é a produtividade do trabalho, que mede o salário implícito dos membros da família. Essa produção máxima é derivada da experiência acumulada, influenciada por fatores culturais e de fertilidade da terra, ou, de outra forma, na ótica da terra, busca-se a maior produção da terra, porque é o meio de obter o produto máximo. Decorre desta hipótese que a terra é explorada com grande intensidade. Então, é óbvio que a produtividade da terra seja elevada na agricultura familiar, quando comparada com a comercial, de mesma tecnologia.

b) Agricultura familiar emprega todos os membros da família. Admitese, assim, ser nulo o custo de oportunidade do trabalho. O mesmo ocorre com a terra. Dessas duas hipóteses decorre que o desemprego da mãode-obra familiar é evitado. Mas, pode acontecer de os membros da família trabalharem fora da fazenda e de ela ter de contratar trabalho.

c) A escolha da tecnologia é muito influenciada por fatores culturais, 
visto que a tecnologia é uma forma de expressão cultural. Na agricultura capitalista, a tecnologia é avaliada por sua rentabilidade. A decisão de escolha da tecnologia é motivada pelo lucro, e não se apega a nenhuma tecnologia, a não ser por dificuldades de mudança que são impostas por um mercado imperfeito de capital.

d) A evolução leva a agricultura familiar a utilizar insumos comprados do mercado. Em relação aos insumos comprados, não há como fugir da regra de que se expande o uso até o ponto em que a última unidade comprada gera um valor do produto igual ao preço do insumo. Essa regra é respeitada pelos mais severos críticos da economia neoclássica, e não deixa de ser um truísmo. Novamente, tentativa-e-erro ensina a família a fazer a escolha. É claro que o conhecimento da coletividade tem papel importante, mas aqui reside uma dificuldade - o padrão cultural da tecnologia é difícil de solidificar-se num mundo de mudanças. Portanto, a adoção da tecnologia não implica a sua culturização. Quanto à escolha de tecnologia, a evolução predita é para o padrão da agricultura capitalista. Não se ama a tecnologia; ela é adotada apenas por ser conveniente. Permanece, contudo, a premissa de a terra e o trabalho familiar não terem custo de oportunidade de mercado, ou, em outras palavras, este não é levado em conta pela família na alocação de terra e trabalho. Mas, agora, quer se maximizar o resíduo que sobra depois de se remunerarem os fatores comprados no mercado, com a condição de pleno emprego do trabalho familiar e da terra. Assim, mesmo com a compra de insumos no mercado, a agricultura família busca, novamente, intensificar o uso da terra e o emprego dos membros da família, e não há nenhuma surpresa pelas produtividades elevadas, na comparação com a agricultura capitalista, de tecnologia semelhante.

e) A agricultura familiar divide, eqüitativamente, entre os membros da família o produto do estabelecimento. Para quem gosta da função de utilidade, há somente uma função de utilidade para toda a família, ou, se for preferido, o conjunto de curvas de indiferença é o mesmo. A função de utilidade depende do produto e do lazer. Obviamente, é imposta pelo chefe de família. A forma das curvas de preferência é peculiar e resulta 
em equilíbrio pelo qual se procura empregar todos os membros da família. No modelo de produção, o equilíbrio de subsistência está no ponto máximo de produção. Isso somente acontece com uma forma peculiar das curvas de indiferença². Quando a agricultura familiar abre-se para o mercado, a imposição de uma única função de utilidade e, peculiar ainda, fica insustentável e desaparece o equilíbrio de subsistência. Oferta e demanda não são mais simultaneamente determinadas (Nakajima, 1986).

f) O agricultor familiar escolhe a cesta de produtos, considerando-se, apenas, o bem-estar da família, e não o bem-estar dos citadinos.

Seguem-se as implicações das premissas:

1) Sob a hipótese de que a agricultura familiar distribua, equiitativamente, o produto entre os membros da família e queira manter os filhos no estabelecimento, com poucas transações com o exterior, o bem-estar máximo será equivalente à produção máxima dos recursos que o estabelecimento comanda - predominantemente terra, porque será considerada mão-de-obra fixa, já que a família manterá todos os membros plenamente ocupados. A agricultura familiar maximizará, portanto, a produção, se não comprar insumos no mercado, e a renda líquida, quando adquirir insumos, considerando-se que utilizará plenamente a terra e o trabalho, ou seja, serão considerados nulos os custos de oportunidade da terra e do trabalho. Por isto, maximizará a produção da terra, visto que é a maneira de obter o maior bem-estar para o núcleo familiar. No entanto, o máximo é determinado pelo conhecimento coletivo e por fatores culturais, pois não é uma decorrência de solução de um modelo complexo de produção. Deve-se esperar expressiva variação dessa produtividade, porque a terra é muito heterogênea, e o conhecimento é também coletivo, entre estabelecimentos, municípios, estados e regiões. A variação será reduzida pela compra de insumos que aumentem a capacidade de

\footnotetext{
${ }^{2}$ A curva de indiferença que tangencia a função de produção, no caso, no ponto máximo, equivale ao máximo de bem-estar da família, respeitada a restrição da função de produção. Neste ponto, a função de utilidade atinge o máximo. Mas esta conclusão, em que há coincidência dos dois máximos, depende de uma função de uma utilidade peculiar. Neste contexto, diz-se que a produtividade máxima do trabalho é uma medida de bem-estar da família.
} 
produção da terra; assim, a variação máxima, devida à heterogeneidade da terra, ocorrerá naquela agricultura que utilizar somente terra e trabalho.

Em razão do processo de decisão da agricultura familiar, que maximizará produção e manterá os membros ocupados, a produtividade do trabalho será uma medida de bem-estar da agricultura familiar. Revela o salário médio dos membros da família, em termos da produção do estabelecimento; obviamente, trata-se de um salário definido pela família, e não pelo mercado.

No caso da compra de volume significativo de insumos, a renda que sobrar, depois de serem pagos os insumos comprados, será maximizada. Na presunção de fixar-se o nível de insumos adquiridos, razões de natureza cultural podem explicá-lo, se novamente maximizar-se a produção. Outra vez, não haverá surpresa de maior produtividade na terra da agricultura familiar.

A área por trabalhador expressará o grau de mecanização e outros arranjos tecnológicos para poupar mão-de-obra. Aumentará, acentuadamente, dos menores para os maiores estabelecimentos e mostrará uma capacidade maior da agricultura familiar de empregar, o que está dentro de sua lógica de decisão. Quando for baixa, será preocupante, porque sem a mecanização a agricultura familiar se autolimitará na exploração do potencial do estabelecimento.

2) O agricultor comercial maximizará renda líquida, considerando-se as restrições a que se submeter e o risco. A produtividade da terra nunca equivalerá ao máximo possível. Se usasse os mesmos insumos da agricultura familiar, necessariamente teria a produtividade da terra menor que a da agricultura familiar. Como, na grande maioria dos casos, usa tecnologia diferente, sua produtividade da terra pode superar à da agricultura familiar, pelo efeito tecnologia apenas.

Se toda a agricultura fosse familiar ou comercial, o índice de produtividade da terra deveria ter variação bem menor, por classe de área. Obser- 
va-se, no cenário brasileiro, enorme variação da produtividade da terra, à medida que a área cresce. Em todas as regiões, ela é bem mais elevada nas classes de áreas menores, decrescendo acentuadamente com a área do estabelecimento. Trata-se de uma prova da acentuada heterogeneidade da nossa agricultura. Como o índice de produtividade da terra é muito maior para os estabelecimentos de menos de cem hectares, todos, exceto cerca de 519 mil, correspondem à lógica da agricultura familiar de buscar o pleno uso desse recurso; portanto, a grande maioria desses estabelecimentos está envolvida na agricultura familiar, com predominância daquela pouco relacionada com o mercado. Se fosse a agricultura familiar moderna, as diferenças de fertilidade da terra teriam sido compensadas pelo uso de insumos modernos, reduzindo, fortemente, sua variabilidade.

3) Com os dados do censo, é impossível isolar-se a agricultura familiar, que se modernizou, daquela mais tradicional. Por isto, a tabela, que se encontra no final desta seção, tem o defeito de misturar agricultores de grande porte, atrasados e modernos, com agricultores familiares, o que mudou o paradigma de decisão para o da agricultura comercial e aquela isolada do mercado. Com essas limitações, verifica-se que a tabela mostra acentuada queda da produtividade da terra, quando varia das classes de menor área para as de maior área. Assim, trata-se de uma evidência indireta da importância da agricultura familiar, apenas isto. A tabela revela acentuada queda na produtividade do trabalho, dos maiores estabelecimentos para os menores, sendo os níveis médios muito baixos. Assim, a produtividade do trabalho segue a lógica da prioridade do emprego, motivo das políticas públicas diferenciadas para a agricultura familiar, com o objetivo de melhorar o bem-estar dos membros da família.

4) Seja $\hat{L}$ a quantidade de trabalho que corresponde à produção máxima, ambos determinados por tentativa-e-erro, com base na experiência acumulada. Seja ${ }^{*}$ o máximo de horas trabalhadas pela família, respeitando-se tradições e costumes. Nenhum exercício de otimização é feito 
para determinar os dois valores, e nem se supõe existência de função de produção.

a. Se $\hat{L}^{\mathrm{e}}{ }_{L}^{*}$ forem iguais, não haverá falta de trabalho, desde que a produção se ajuste à demanda da família. Caso contrário, será preciso aumentar as horas trabalhadas, no caso, fora do estabelecimento, sacrificando o lazer para atender à demanda de bens da família.

b. Se ${ }_{L}^{*}$ for maior que $\hat{L}$, então haverá sobra de mão-de-obra. Emprego extra será buscado fora do estabelecimento, nas cidades ou em atividades de agroindústria familiar, e, recentemente, nas invasões do MST.

c. Se $\hat{L}$ for maior que ${ }_{L}^{*}$ haverá falta de trabalhadores e, conseqüentemente, haverá contratação, se esta for economicamente justificada. Mas o pagamento não se assenta no regime igualitário da família; em muitos casos, há troca de serviços, mutirões, etc. A regra de o valor da produção do trabalho da última unidade contratada ser igual ao salário é incorporada à decisão da família.

4. Dados do censo 1995/96 indicam o uso de fertilizantes e de outros insumos e índice de mecanização, potência do trator por hectare, bem mais elevados nos estabelecimentos de menos de cem hectares (Alves, Lopes e Contini, 1999), o que é muito mais constante no Sul e no Sudeste. Trata-se de uma evidência de abertura desses estabelecimentos para o mercado, o que enfraquece, em demasia, o uso de índices de produtividade, como os que foram discutidos. Nesse contexto, eles perdem a interpretação cristalina, que foi dada, de que é mais apropriado o emprego da produtividade total dos fatores, o que não se pratica entre os defensores da agricultura familiar. Pela teoria e pelas evidências disponíveis, não está definida a relação desse tipo de índice com a produtividade da terra, há, inclusive, evidências de correlação negativa entre eles (Alves e Souza, 2000). 
As duas últimas colunas da Tabela 1 merecem uma explicação. Tomouse o logaritmo da relação $\frac{R B}{L} \equiv \frac{R B}{A} * \frac{A}{L}$, que foi transformada numa soma. Dividiram-se ambas as parcelas por $\log \left(\frac{R B}{L}\right)$, e ambos os lados foram multiplicados por 100. O lado esquerdo ficou igual a 100. Do lado direito, tem-se a contribuição, em porcentagem, da produtividade da terra e da área que cada trabalhador cultiva. A contribuição do trabalho decresce com as classes de área, enquanto a contribuição da terra cresce com as classes de área. No Nordeste e no Norte, as variações são mais acentuadas que no Sudeste e no Sul, cuja agricultura é muito mais avançada. As últimas duas colunas contam a mesma história: heterogeneidade da agricultura e uso mais intenso da terra nos extratos até cem hectares.

Ressalta-se, ainda, a baixa produtividade do trabalho, o que significa que a remuneração dos membros da família, nas classes de área da agricultura familiar, não compete com o salário mínimo. Isso indica uma propensão da família a deixar o estabelecimento, a buscar trabalho nas cidades e na agricultura comercial, e a desenvolver atividades de agroindústria caseira. Sem tecnologias e políticas públicas que aumentem o excedente comercializável do estabelecimento, ele, tão-somente, não dará renda digna à família. Implicitamente, admitiu-se ser zero a produtividade marginal do trabalho. $\mathrm{Na}$ agricultura familiar, a produtividade média do trabalho nunca é igual à marginal. Assim, não há contradição, conforme a tabela, no fato de a produtividade do trabalho ser positiva, e a produtividade marginal, zero.

5. Como a escolha da cesta de produtor da agricultura familiar visa ao seu bem-estar e não ao da urbis, o fato de ela optar por grupo de produtos diferentes daqueles da agricultura capitalista significa algo ruim e não bom, como se assevera. Indica que ela sofre restrições que prejudicam seu bem-estar. Portanto, o argumento em sua defesa é falso, o que implica que há restrições que precisam ser eliminadas. 
Tabela 1 - Distribuição do valor da produção mensal dos estabelecimentos e decomposição da produtividade do trabalho em produtividade da terra e área-trabalhador, por regiões e classes de área. Censo 1995/96

\begin{tabular}{|c|c|c|c|c|c|c|}
\hline $\begin{array}{l}\text { Classes } \\
\text { (em ha) }\end{array}$ & $\begin{array}{c}\text { Renda bruta por } \\
\text { estabelecimento } \\
\text { (R\$/mês) }\end{array}$ & $\begin{array}{c}\text { Produtividade da } \\
\text { terra } \\
\text { (R\$/ha/mês) }\end{array}$ & $\begin{array}{c}\text { Área por } \\
\text { trabalhador } \\
\text { (ha/trabalhador) }\end{array}$ & $\begin{array}{c}\text { Produtividade do } \\
\text { trabalho } \\
\text { (R\$/trab./mês) }\end{array}$ & $\begin{array}{c}\text { Contribuição do } \\
\text { trabalho } \\
(\%)\end{array}$ & $\begin{array}{c}\text { Contribuição da } \\
\text { área } \\
(\%) \\
\end{array}$ \\
\hline \multicolumn{7}{|c|}{ Norte } \\
\hline$<10$ & 173,01 & 48,06 & 0,98 & 46,93 & $-0,62$ & 100,62 \\
\hline$[10,20)$ & 236,30 & 17,60 & 3,31 & 58,28 & 29,46 & 70,54 \\
\hline$[20,50)$ & 227,42 & 7,10 & 7,83 & 55,60 & 51,21 & 48,79 \\
\hline$[50,100)$ & 270,79 & 4,04 & 15,74 & 63,63 & 66,37 & 33,63 \\
\hline$[100,200)$ & 344,54 & 2,86 & 26,69 & 76,42 & 75,74 & 24,26 \\
\hline$[200,500)$ & 670,32 & 2,24 & 61,85 & 138,80 & 83,61 & 16,39 \\
\hline$[500,1000)$ & 1322,73 & 1,92 & 126,69 & 243,40 & 88,12 & 11,88 \\
\hline$[1000,10000)$ & 3741,38 & 1,53 & 276,31 & 422,93 & 92,96 & 7,04 \\
\hline$>10000$ & 31616,63 & 1,15 & 647,50 & 745,81 & 97,86 & 2,14 \\
\hline Região & 366,85 & 2,79 & 31,15 & 86,87 & 77,03 & 22,97 \\
\hline \multicolumn{7}{|c|}{ Nordeste } \\
\hline$<10$ & 71,18 & 27,53 & 0,84 & 23,20 & $-5,45$ & 105,45 \\
\hline$[10,20)$ & 169,31 & 12,52 & 3,64 & 45,61 & 33,85 & 66,15 \\
\hline$[20,50)$ & 232,53 & 7,55 & 7,83 & 59,11 & 50,46 & 49,54 \\
\hline$[50,100)$ & 376,43 & 5,59 & 15,31 & 85,60 & 61,32 & 38,68 \\
\hline$[100,200)$ & 716,05 & 5,35 & 25,70 & 137,60 & 65,93 & 34,07 \\
\hline$[200,500)$ & 1440,61 & 4,82 & 43,40 & 209,41 & 70,55 & 29,45 \\
\hline$[500,1000)$ & 3126,42 & 4,65 & 63,36 & 294,41 & 72,98 & 27,02 \\
\hline$[1000,10000)$ & 8709,51 & 4,23 & 131,01 & 554,64 & 77,16 & 22,84 \\
\hline$>10000$ & 91632,82 & 4,66 & 160,25 & 746,12 & 76,75 & 23,25 \\
\hline Região & 222,09 & 6,55 & 9,58 & 62,72 & 54,59 & 45,41 \\
\hline \multicolumn{7}{|c|}{ Centro-Oeste } \\
\hline$<10$ & 310,82 & 63,25 & 1,64 & 103,97 & 10,70 & 89,30 \\
\hline$[10,20)$ & 352,58 & 23,79 & 4,62 & 109,84 & 32,55 & 67,45 \\
\hline$[20,50)$ & 477,48 & 14,37 & 9,83 & 141,28 & 46,16 & 53,84 \\
\hline$[50,100)$ & 641,09 & 9,14 & 20,06 & 183,36 & 57,54 & 42,46 \\
\hline$[100,200)$ & 1142,98 & 8,27 & 36,44 & 301,17 & 63,00 & 37,00 \\
\hline$[200,500)$ & 2425,47 & 7,62 & 72,53 & 552,82 & 67,84 & 32,16 \\
\hline$[500,1000)$ & 4828,30 & 6,86 & 136,74 & 937,53 & 71,87 & 28,13 \\
\hline$[1000,10000)$ & 12724,40 & 5,02 & 299,98 & 1505,20 & 77,95 & 22,05 \\
\hline$>10000$ & 51109,16 & 2,15 & 698,13 & 1499,76 & 89,54 & 10,46 \\
\hline Região & 2318,25 & 5,18 & 106,95 & 553,51 & 73,97 & 26,03 \\
\hline \multicolumn{7}{|c|}{ Sudeste } \\
\hline$<10$ & 409,65 & 92,05 & 1,54 & 141,96 & 8,74 & 91,26 \\
\hline$[10,20)$ & 609,32 & 41,82 & 4,41 & 184,61 & 28,46 & 71,54 \\
\hline$[20,50)$ & 899,66 & 27,92 & 8,72 & 243,61 & 39,42 & 60,58 \\
\hline$[50,100)$ & 1502,20 & 21,23 & 16,05 & 340,78 & 47,60 & 52,40 \\
\hline$[100,200)$ & 2731,09 & 19,52 & 25,58 & 499,28 & 52,18 & 47,82 \\
\hline$[200,500)$ & 4878,74 & 15,98 & 40,75 & 651,22 & 57,22 & 42,78 \\
\hline$[500,1000)$ & 10671,86 & 15,57 & 60,71 & 945,31 & 59,93 & 40,07 \\
\hline$[1000,10000)$ & 34692,36 & 16,94 & 76,77 & 1300,69 & 60,54 & 39,46 \\
\hline$>10000$ & 233671,90 & 12,24 & 130,47 & 1596,35 & 66,05 & 33,95 \\
\hline Região & 1560,68 & 20,48 & 18,64 & 381,65 & 49,21 & 50,79 \\
\hline \multicolumn{7}{|c|}{ Sul } \\
\hline$<10$ & 396,32 & 78,79 & 1,79 & 141,30 & 11,80 & 88,20 \\
\hline$[10,20)$ & 612,15 & 43,59 & 4,37 & 190,66 & 28,10 & 71,90 \\
\hline$[20,50)$ & 1015,68 & 33,75 & 8,53 & 287,95 & 37,86 & 62,14 \\
\hline$[50,100)$ & 1800,23 & 26,28 & 17,96 & 471,96 & 46,91 & 53,09 \\
\hline$[100,200)$ & 2928,86 & 21,20 & 30,29 & 642,18 & 52,76 & 47,24 \\
\hline$[200,500)$ & 5323,06 & 17,35 & 54,41 & 943,96 & 58,34 & 41,66 \\
\hline$[500,1000)$ & 10038,47 & 14,63 & 82,90 & 1212,67 & 62,22 & 37,78 \\
\hline$[1000,10000)$ & 23033,12 & 12,28 & 123,78 & 1520,10 & 65,77 & 34,23 \\
\hline$>10000$ & 252523,10 & 13,21 & 204,74 & 2704,00 & 67,34 & 32,66 \\
\hline Região & 1083,83 & 24,49 & 13,12 & 321,23 & 44,59 & 55,41 \\
\hline
\end{tabular}

Fonte: Alves, Lopes e Contini, 1999. 


\section{Modelo de produção}

A premissa do modelo de produção é a existência da função de produção ${ }^{3}$. Para se manter a análise em duas dimensões, quando insumos são adquiridos no mercado, teve de se fixar o nível desses insumos, restrição fácil de ser eliminada, com auxílio de um pouco mais de matemática. $\mathrm{O}$ modelo de produção permite o exercício de maximização, mas a função de produção pode ser determinada por fatores culturais, bem como os pontos ótimos. É uma forma simples de expressar as realidades da agricultura familiar e suas consequiências, apenas isto, daí, apresentam-se três possibilidades. As implicações das três possibilidades são as seguintes:

Têm-se três modelos de produção. No eixo horizontal está o trabalho e no vertical, o produto ${ }^{4}$. A linha marcada por a representa uma função de produção, que é sempre crescente. O produto máximo ocorre quando $\hat{L}{ }^{\mathrm{e}}{ }_{L}^{*}$ são iguais. Neste modelo, não há sobra de trabalho. Pode acontecer de o produto em ${ }_{L}^{*}$ exceder a necessidade da família, que venderá o excesso. Se o produto atender à demanda família, não haverá comércio. Poderia ser econômico contratar trabalho; muitas vezes isso acontece, outras, não, devido a fatores culturais. O produto ficará aquém das necessidades da família; se for econômico, haverá contratação de trabalho; caso contrário, as horas de lazer serão sacrificadas.

\footnotetext{
${ }^{3}$ Admitindo-se que quem produz mais nunca gaste menos, é possível justificar a existência da função de produção (Varian, 1985), mesmo na presença de fatores de produção fixos. Uma exposição dos trabalhos de Varian, em português, está em Alves (2000), a qual requer bastante matemática.

${ }^{4}$ Somente é possível trabalhar com um eixo horizontal e um vertical, duas dimensões, fixando-se o nível dos insumos adquiridos do mercado, ou, então, quando a tecnologia usa terra e trabalho.
} 


\section{Produção como função do trabalho}

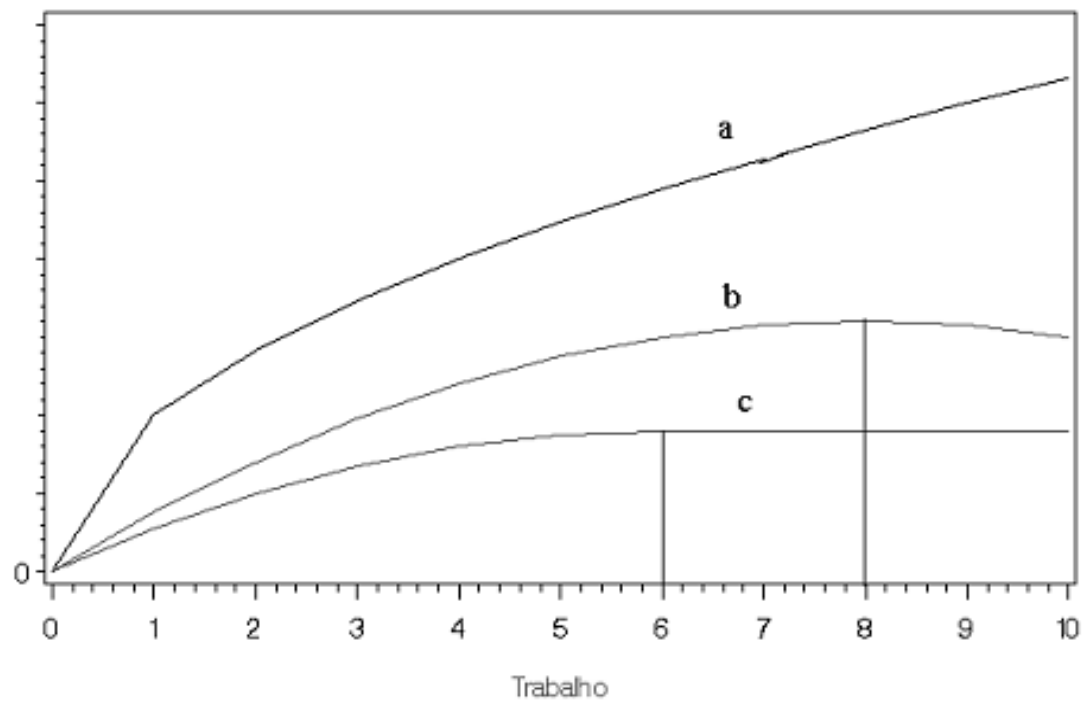

No modelo expresso pela linha $\mathbf{b}$, a produção máxima ocorre no ponto 8 . Depois dele, a produção decresce. Se a mão-de-obra familiar exceder ${ }^{*}=8$, haverá sobra de trabalho familiar, e o excedente reduzirá a produção, se este for utilizado. É possível reduzir as horas trabalhadas, ou o trabalho fora do estabelecimento será aconselhável para o excedente.

Se $\hat{L}=8<L^{*}$, trabalho será contratado, de acordo com a regra que iguala o valor da produção da última unidade contratada ao salário. Se a produção não atender à demanda da família, o emprego de mais insumos deslocará b para cima e poderá ajustar a demanda à oferta, em nível de estabelecimento.

No modelo da linha c, que é a base da formulação de Arthur Lewis, rigorosamente expressa em Jorgenson (1969), a produção máxima ocorrerá em $\hat{L}=6$, e a produção ficará constante daí para frente. À direita 
do ponto, o trabalho não adiciona nada à produção: produtividade marginal do trabalho iguala-se a zero. Logo, se $L^{*}>\hat{L}$, haverá excedente de trabalho familiar, coerente com a expansão das atividade em agroindústria familiar, trabalho fora do estabelecimento em tempo parcial e migração rural-urbana. Se a desigualdade for revertida, poder-se-á contratar trabalho pela regra de remuneração já aludida. Assim, somente o modelo a não implica excedente de trabalho familiar.

\section{Dilemas da proposta da agricultura familiar}

1) Como preservar o método de decisão da agricultura familiar dentro de uma economia competitiva? Se o diferencial de salário entre as cidades superar o salário implícito a que a família se atribui, o custo de oportunidade do trabalho tomará vulto, o que significa mudança radical no processo de decisão.

2) A agricultura familiar não é um único animal. Pouco mais usa que trabalho e terra no Nordeste, onde ela se encontra perto dos milhões. As áreas mais favoráveis estão sob a forte pressão da agricultura familiar capitalista e da de médio e grande porte. Restarão as áreas de recursos naturais pobres; para muitas delas, uma solução agronômica é complicadíssima. No Sul e Sudeste, a agricultura familiar significa pouco em relação à do Nordeste, e muda rapidamente o padrão de decisão para agricultura ainda familiar, mas capitalista. No Centro-Oeste, a agricultura familiar tem pouca expressão.

3) A dinâmica da agricultura capitalista influenciará, dramaticamente, a agricultura familiar, em todas as áreas, inclusive na direção de explorar poucas culturas. Tem o Tesouro Nacional recurso para obstar essa marcha? Quem decidirá se ela é indesejável, ou não? De cima para baixo, sob os ventos de ideologias que ignoram a presença dominante do regime capitalista na nossa sociedade ou democraticamente?

4) Quem pode ser contra preservar a cultura local? A questão é se isso é factível. É isto que as comunidades querem? Novamente, forças 
macrossociais, impulsionadas pela comunicação de massa, que se assenta, principalmente, no Rio de Janeiro e em São Paulo, exercem influência avassaladora em nossa sociedade, até no modo de falar regional.

5) Hayami e Ruttan documentaram, em vários países, que os métodos tradicionais de transformação, inclusive a seleção de variedades que não violentem a cultura local, trouxeram, no máximo, o incremento anual de $1 \%$ da produção (Hayami e Ruttan, 1988). No Brasil, precisa-se de, pelo menos, $3 \%$ de incremento anual da produção. Portanto, pequenos incrementos de produtividade nos cultivares locais deixarão a agricultura familiar tão pobre como está. É isto que os agricultores familiares querem? É claro que é importante preservar as variedades locais, na ótica de preservação de recursos genéticos. Será possível melhorar os cultivares locais, sem mudanças radicais? Não se está fazendo pouco caso da inteligência dos milhares de agricultores que trabalharam com esses cultivares por muitos anos? Alguém pode ser melhor do que eles, sem mudanças radicais?

6) Há certa resistência ao modo de decidir e à produção da agricultura capitalista. Basicamente, como se viu, a agricultura capitalista escolhe a tecnologia e o vetor de insumos, com vistas em maximizar a renda líquida. É óbvio que a agricultura familiar acabará adotando o mesmo critério, num mundo competitivo e aberto ao comércio exterior, e, assim, transformar-se-á em agricultura familiar capitalista. Não há como colocar um muro que evite a contaminação da agricultura familiar pela capitalista, estabelecendo-se os critérios da FUNAI como paradigma para as políticas públicas voltadas para aquela agricultura.

7) Os meios de comunicação de massa exaltam o consumo, o valor da educação, da saúde, de médicos sofisticados, o automóvel, as viagens internacionais e milhares de outros bens indisponíveis no campo. Todos querem entrar nessa festa que exige muito dinheiro e trabalho. Novamente, é possível cercar a agricultura familiar para que ela não se contamine pelos hábitos de consumo urbanos? Entre os mais velhos, admitese essa possibilidade, mas a juventude optará pela festa, terá, por isto, que ganhar muito mais dinheiro. Parte migrará, e a outra parte que restar 
exigirá o máximo de renda líquida do estabelecimento, mudando, dramaticamente, os métodos de decisão para os da agricultura capitalista. A agricultura familiar transformar-se-á em agricultura familiar capitalista. Assim, é fútil tentar impor uma barreira tecnológica e de métodos de decisão que separem as duas agriculturas. $\mathrm{O}$ agricultor familiar batalhará para capitalizar-se e para buscar conhecimentos que eliminem o imenso fosso que existe entre os dois modos de fazer. Estamos em condições de ofertar o crédito rural com a flexibilidade necessária? E a extensão rural? Sem a solução dessas duas perguntas, o quê produzimos, além de retórica?

8) O modo de produção da agricultura familiar enfatiza a intensificação do uso da terra. É isto pertinente diante dos critérios de sustentabilidade?

9) Há um mito, de circulação internacional, que reza que a agricultura familiar deva utilizar tecnologias pouco intensivas em capital, visto ser estas escassas, no mundo subdesenvolvido. Numa economia aberta, essa hipótese é sem fundamento. No longo prazo, isso é menos razoável ainda, porque o capital será produzido na fazenda e nas fábricas se houver demanda, o que obstará o aumento de sua produção. As tecnologias novas cristalizam-se no capital. O resíduo do crescimento econômico não explicado pelo incremento do capital, quando corretamente medido, é pouco expressivo (Jorgenson, 1995). Restringir o acesso da agricultura familiar ao capital, em nome de uma falsa escassez, é condená-la a perder a competição para a agricultura capitalista, é condená-la ao atraso tecnológico e à pobreza.

10) Outro mito é que há tecnologias específicas à agricultura familiar que não servem ao modo de produção da agricultura capitalista. Como salientado, o agricultor capitalista escolhe a tecnologia por razões de lucro. Se uma tecnologia for rentável para a agricultura familiar, o que impedirá a capitalista de adaptar-se a ela e de adotá-la? Aí, estão a agricultura orgânica e o feijão, em expansão acelerada na agricultura capitalista. Se uma tecnologia for rentável para a agricultura capitalista, não será melhor verificar as restrições que impedem sua adoção pela agricultura familiar e removê-las? Os argumentos de especificidade da 
tecnologia para a agricultura familiar, no fundo, escondem o objetivo de impor à família um modo específico de produção, e o método de fazê-lo não é democrático, ou seja, ninguém consultou os agricultores, se é isto que desejam. Por isso e por pressões do mercado, esse modelo, numa sociedade democrática e pluralista, tem pouca chance de emplacar.

11) Ouvem-se críticas ao modo de produção capitalista, baseadas em monitoramento pouco convincente e em análises parciais que não levam em conta a necessidade de área menor para atender à demanda. Somente para argumentar, aceita-se que a crítica seja bem fundamentada. Se a tecnologia não for proibida, o que impede a agricultura capitalista de adotá-la, expandir a produção e dominar o mercado? Pelo contrário, as tecnologias que enfatizam a qualidade do produto são intensivas em capital, e muitas estão fora do alcance da agricultura familiar, se os critérios de financiamento e o montante de crédito para investimento não forem, drasticamente, reformulados.

12) Como eliminar as restrições que determinam uma cesta de produtos peculiar para a agricultura familiar?

\section{Conclusões}

Finalizando-se o trabalho, relacionam-se as principais conclusões:

1) As políticas públicas em favor da agricultura familiar são justificadas pela sua expressividade, dado o percentual de emprego que oferece, dada sua baixa remuneração do trabalho, além de garantir a existência de milhões de pequenos empreendedores.

2) A produtividade da terra indica o vulto da agricultura familiar, e não que ela seja mais eficiente que a capitalista.

3) A produtividade do trabalho é uma medida de bem-estar e é muito menor nos extratos até cem hectares. Está em nível igual ou menor do que um salário mínimo, razão pela qual as políticas públicas têm de propiciar o aumento desta, como primeira prioridade. 
4) A agricultura familiar escolhe a tecnologia e o nível de insumos para maximizar o emprego de membros da família e seu bem-estar. Mas, quando contrata trabalho, é de acordo com a regra do mercado, pela qual a última unidade contratada tem que gerar um valor de produção igual ao salário.

5) No contexto de uma agricultura capitalista dinâmica, a agricultura familiar mudará as regras de decisão, considerando-se os custos de oportunidade da terra e do trabalho como critério de decisão fundamental. Prevê-se sua evolução para a agricultura familiar capitalista, que somente substituirá o trabalho familiar pelo assalariado para aumentar o bem-estar dos filhos e dar-lhes melhor futuro.

6) É pouco relevante o argumento de que a agricultura familiar abastece o país, principalmente os citadinos mais pobres. $\mathrm{O}$ bem-estar urbano não faz parte de sua lógica de decisão. Se explora uma cesta de produto específica, é porque, dadas as restrições a que se sujeita, não tem condições de fazer escolhas compatíveis com a agricultura capitalista. Romper essas restrições é muito importante para o bem-estar dos membros da família.

\section{Referências bibliográficas}

ALVES, Eliseu; LOPES, Mauro; e CONTINI, Elisio. O Empobrecimento da Agricultura Brasileira, Revista de Política Agrícola, ano VIII, n ${ }^{\circ}$ 03, jul./ag./set., 1999.

ALVES, Eliseu; SOUZA, Geraldo da Silva. Tópicos de política agrícola. Em Santos, Maurinho Luiz e Vieira Wilson da Cruz (eds.) Agricultura na virada do milênio: 145-167, Universidade Federal de Viçosa, 2000.

ALVES, Eliseu. Teoria da produção: métodos não-paramétricos, Brasília, Embrapa, 2000.

HAYAMI, Yujiro e RUTTAN, V. W. Desenvolvimento agrícola: teoria e experiência internacionais, Brasília, Embrapa, 1988. 
JORGENSON, Dale W. The role of agriculture in economic development: classical versus neo classical models of growth. Em Wharton, Jr., Clifton (ed). Subsistence agriculture and economic development, Chicago, Aldine Publishing Co., p.320-348, 1969.

JORGENSON, Dale W. Productivity, volume 1: postwar U.S. economic growth. Cambridge, the MIT Press, 1996.

NAKAJIMA, C. Subjective equilibrium theory of the family household, New York, Elsevier, 1986.

VARIAN, Hall R. Non-parametric analysis of optimizing behavior with measurement error. Journal of Econometrics: 30, p. 445-458, 1985. 
REVISTA DE ECONOMIA E AGRONEGÓCIO, VOL.1, $N^{\circ} 3$ 